Supporting Information for

\title{
Creation of Controllable High-Density Defects in Silver Nanowires for Enhanced Catalytic Property
}

\author{
Chaoqi Wang, ${ }^{\dagger}$ Zhaorui Zhang, ${ }^{\dagger}$ Guang Yang, ${ }^{*}$ Qiang Chen, ${ }^{\dagger} *$ Yadong Yin, ${ }^{\S}$ \\ and Mingshang $\mathbf{J i n}^{\dagger, *}$
}

${ }^{\dagger}$ Frontier Institute of Science and Technology and School of Chemical Engineering and Technology, Center for Advancing Materials Performance from the Nanoscale (CAMP-Nano), State Key Laboratory for Mechanical Behavior of Materials, Xi'an Jiaotong University, Xi'an, Shaanxi 710049, China

${ }^{*}$ Electronic Materials Research Laboratory, Key Laboratory of the Ministry of Education \& International Center for Dielectric Research, Xi'an Jiaotong University, Xi'an, Shaanxi 710049, China

${ }^{\S}$ Department of Chemistry, University of California, Riverside, California 92521, USA

*Corresponding author. E-mail: jinm@mail.xjtu.edu.cn, chenqiang2204@mail.xjtu.edu.cn. 


\section{Experimental Section}

Chemicals and Materials.

Silver nitrate $\left(\mathrm{AgNO}_{3}\right)$, ethylene glycol $(\mathrm{EG})$, sodium hydrate $(\mathrm{NaOH})$, potassium bromide $(\mathrm{KBr})$, and PVP $(\mathrm{MW} \approx 10000)$ were all obtained from Sigma-Aldrich. Dimethylphenylsilane, n-propanol, and ethyl acetate were obtained from TCI. SBA-15 was obtained by Nathmay. Ethanol, n-hexane, and n-dodecane were obtained from Guang Hua Sci-Tech, Fuyu Fine Chemical, and Aladdin, respectively.

\section{Preparation of Ag Nanowires (NWs).}

In a typical synthesis, a mixture of $34 \mathrm{mg} \mathrm{AgNO}_{3}, 0.375 \mathrm{~mL} \mathrm{EG}$, and $0.25 \mathrm{~mL}$ deionized water was immersed in $200 \mathrm{mg}$ SBA-15 by vibration and ultrasonic. This impregnated sample was transported into the tube furnace under nitrogen protection. Heat the sample from room temperature to $180{ }^{\circ} \mathrm{C}$ in 30 minutes, and then keep the sample at $180{ }^{\circ} \mathrm{C}$ for $90 \mathrm{~min}$. The product was further annealed at different temperatures (e.g. $180{ }^{\circ} \mathrm{C}, 300{ }^{\circ} \mathrm{C}$, and $500{ }^{\circ} \mathrm{C}$ ) for two hours. Afterwards, the products were washed with ethanol three times. Finally, free-standing Ag NWs can be obtained by etching SBA-15 with $5 \mathrm{M} \mathrm{NaOH}$ aqueous solution for 36 hours. The density of defects in Ag nanowires can be adjusted by simply controlling the annealing temperature. The density of structural defects within Ag nanowires decreases with the increase of annealing temperature from $180{ }^{\circ} \mathrm{C}$ to $500{ }^{\circ} \mathrm{C}$.

\section{Preparation of Ag Nanoparticles (NPs).}

In a typical synthesis, a mixture including $108 \mathrm{mg} \mathrm{AgNO}_{3}, 2.1 \mathrm{~g}$ PVP and $30 \mathrm{~mL} \mathrm{H}_{2} \mathrm{O}$ were stirred on magnetic stirring. Then, $0.375 \mathrm{~mL}$ of $0.1 \mathrm{M} \mathrm{NaBH}_{4}$ aqueous solution was added to the mixture. The reaction was stopped after 20 minutes, and the final products were collected through centrifugation and washed with ethanol three times.

\section{Catalytic Evaluation of Ag Catalysts toward Dehydrogenative Coupling Reaction.}


$4 \mathrm{~mL}$ of n-propanol was added in a $20 \mathrm{~mL}$ hard-glass reactor outfitted with a magneton and a rubber stopper. Then, $1 \mathrm{mM}$ dimethylphenylsilane was introduced into the reactor under ultrasonic. The reactor was then transferred to a water bath and preheated at different reaction temperatures (e.g., $25^{\circ} \mathrm{C}, 45^{\circ} \mathrm{C}$, and $65^{\circ} \mathrm{C}$ ) for 10 minutes. After that, the Ag catalysts $(1 \mathrm{~mol} \%)$ were added into the reactor. The reaction was allowed to react for different reaction times. Then, the reactor was taken out and cooled with ice bath to end the reaction quickly. The product was collected for further analysis. For the stability test, the Ag NWs were collected from the catalytic reaction by centrifugation and washed with quantitative n-propanol for next test. The product was purified by chromatography on silica gel with mixed liquids of anhydrous ethyl acetate and hexane for nuclear magnetic resonance (NMR) representation. For GC measurements, a frequently-used reagent, n-dodecane, was selected as an internal standard.

\section{Morphological, Structural, Elemental, and Property Characterizations.}

Transmission electron microscopy (TEM) images were performed using Hitachi HT-7700 operated at $100 \mathrm{kV}$. High-resolution (HR) TEM analyses were taking using JEOL JEM-ARM 200F condenser spherical aberration correction TEM and Philips Tecnai F20 FEG-TEM operated at $200 \mathrm{kV}$. Powder X-ray diffraction (XRD) was charcterized by using a diffractometer (DMAX/A, Rigaku), which operated at $40 \mathrm{kV}$ voltage and $30 \mathrm{~mA}$ current with $\mathrm{Cu} \mathrm{K}$ radiation. Thermal Scientific Nicolet 6700 was used for FT-IR test. Elemental analysis was detected by Agilent 7500CE inductively coupled plasma mass spectrometry (ICP-MS). Agilent 5970C gas chromatography-mass spectrometry (with thermal conductivity detector) and Bruker Avance-400 spectrometer nuclear magnetic resonance (NMR) were used for organic reactions conversion and products structure analyses. 


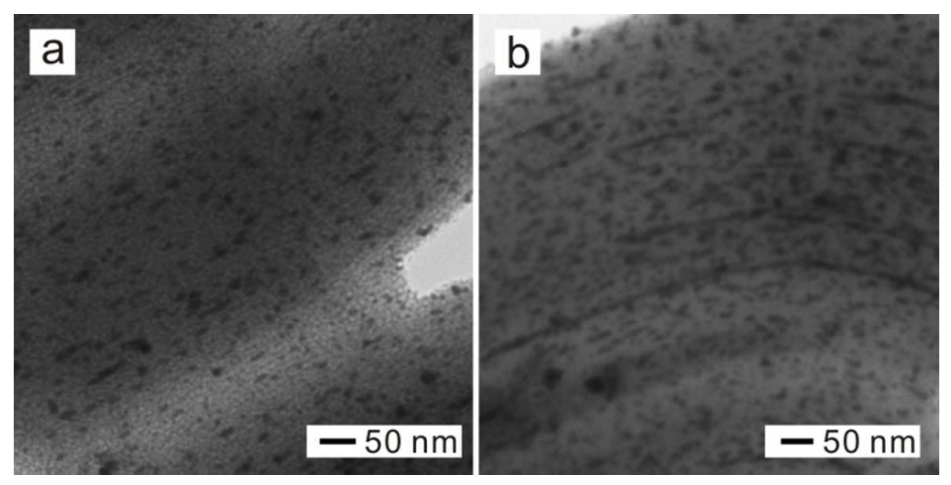

Figure S1. TEM images of the reaction intermediates of Ag nanowires. 


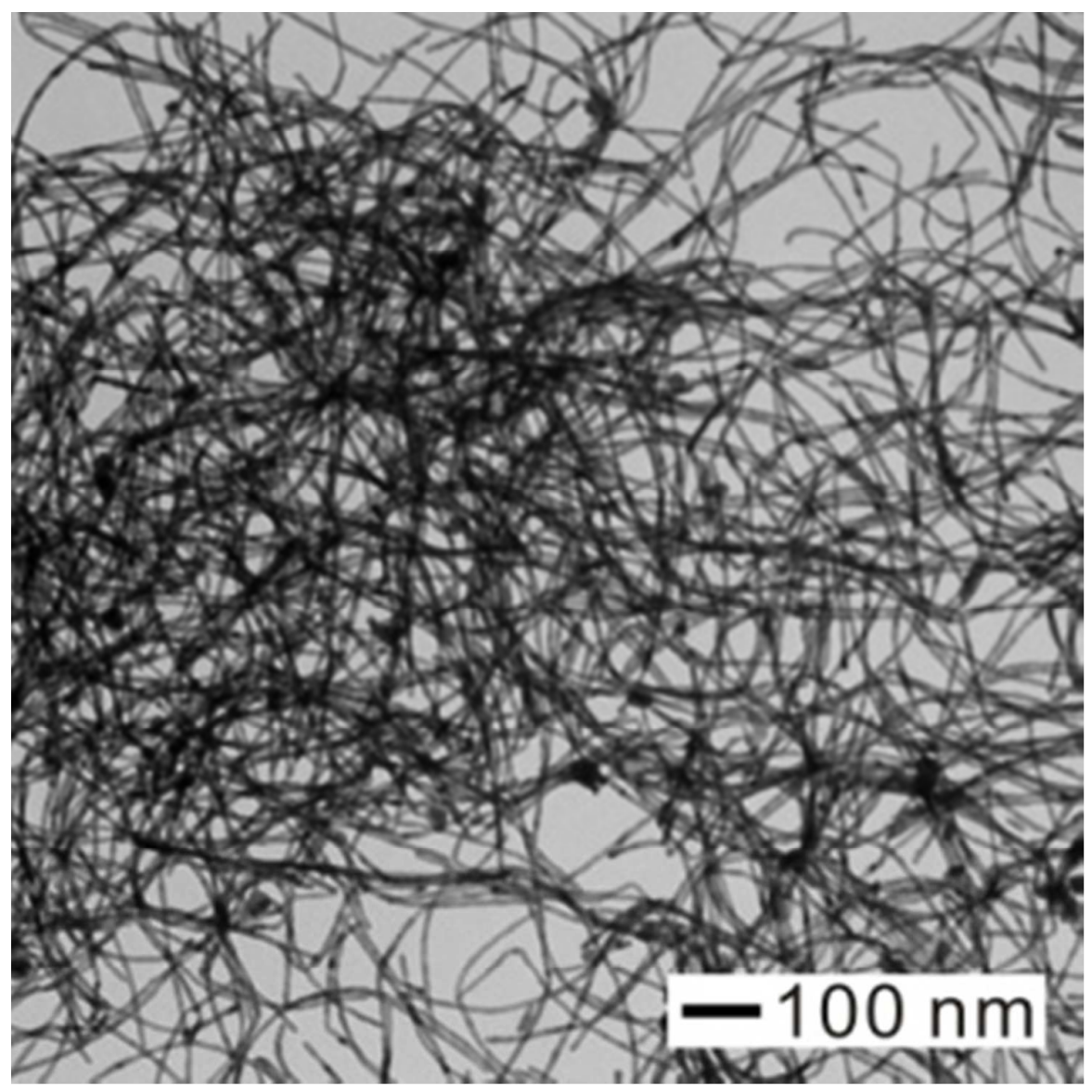

Figure S2. TEM image of Ag nanowires at a low magnification. 


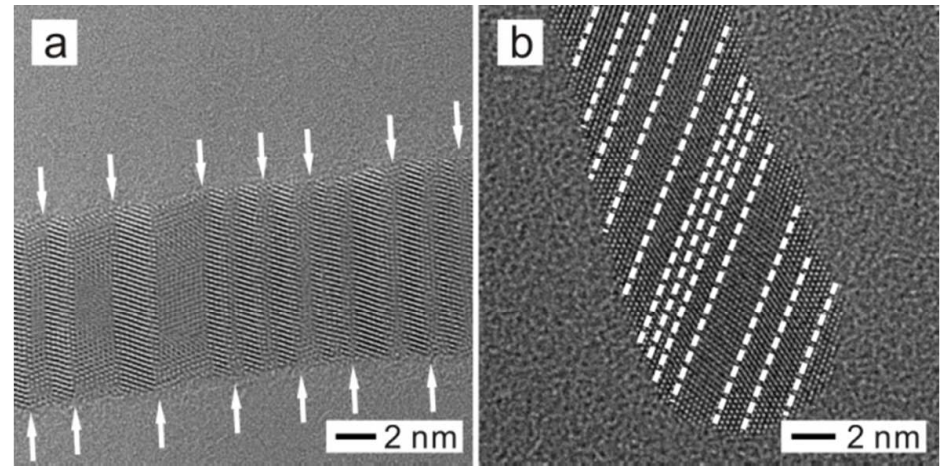

Figure S3. Additional high resolution transmission electron microscope (HRTEM) images of Ag nanowires). a) The white arrows show the twin and stacking faults distribution. b) HRTEM image of one end of an individual Ag nanowire. The images illustrate high-density defects also exist in the end of Ag nanowires, similar to that of the middle part. 


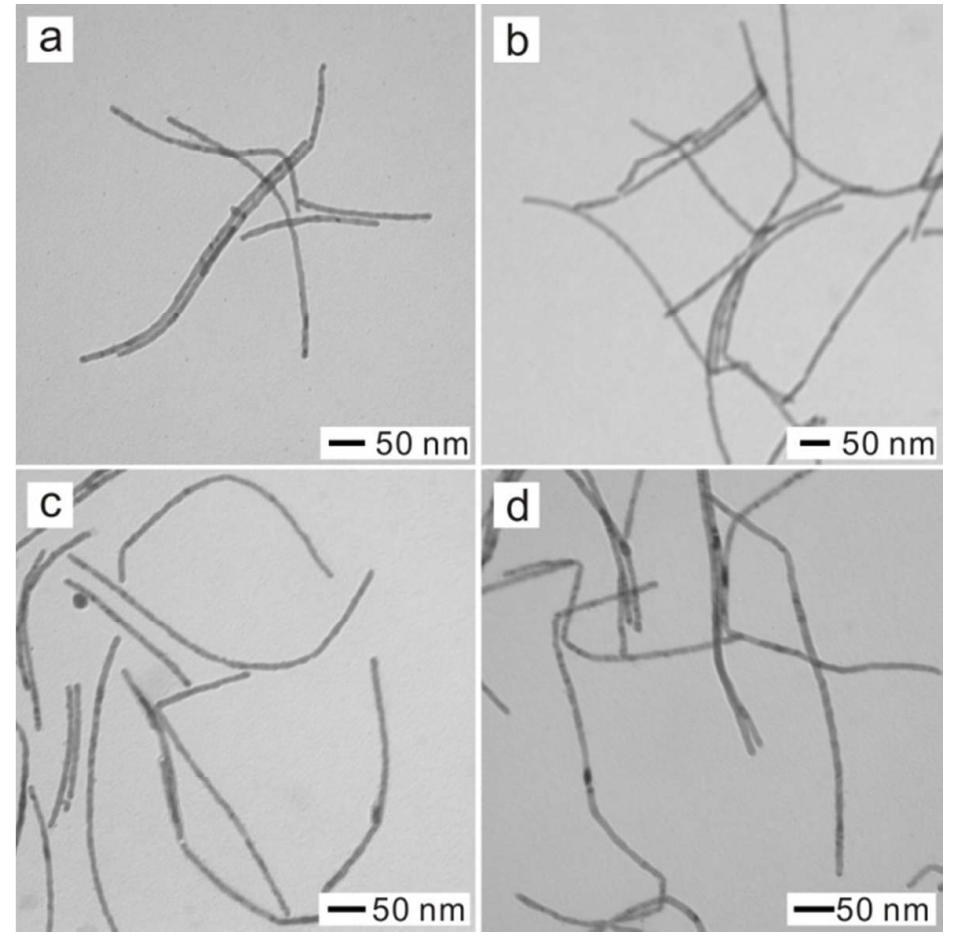

Figure S4. Ag nanowires prepared under the standard condition except of the different concentrations of silver precursor $\left(\mathrm{AgNO}_{3}\right)$. a) $\left.2.13 \mathrm{mg}, \mathrm{b}\right) 4.25 \mathrm{mg}$, c) 8.50 $\mathrm{mg}$, d) $17 \mathrm{mg}$. From the images, we find the concentration of $\mathrm{AgNO}_{3}$ won't significantly change the shape of the final products, implying that the growth of $\mathrm{Ag}$ nanocrystals has been strongly restricted in the one-dimensional pores of SBA-15. 


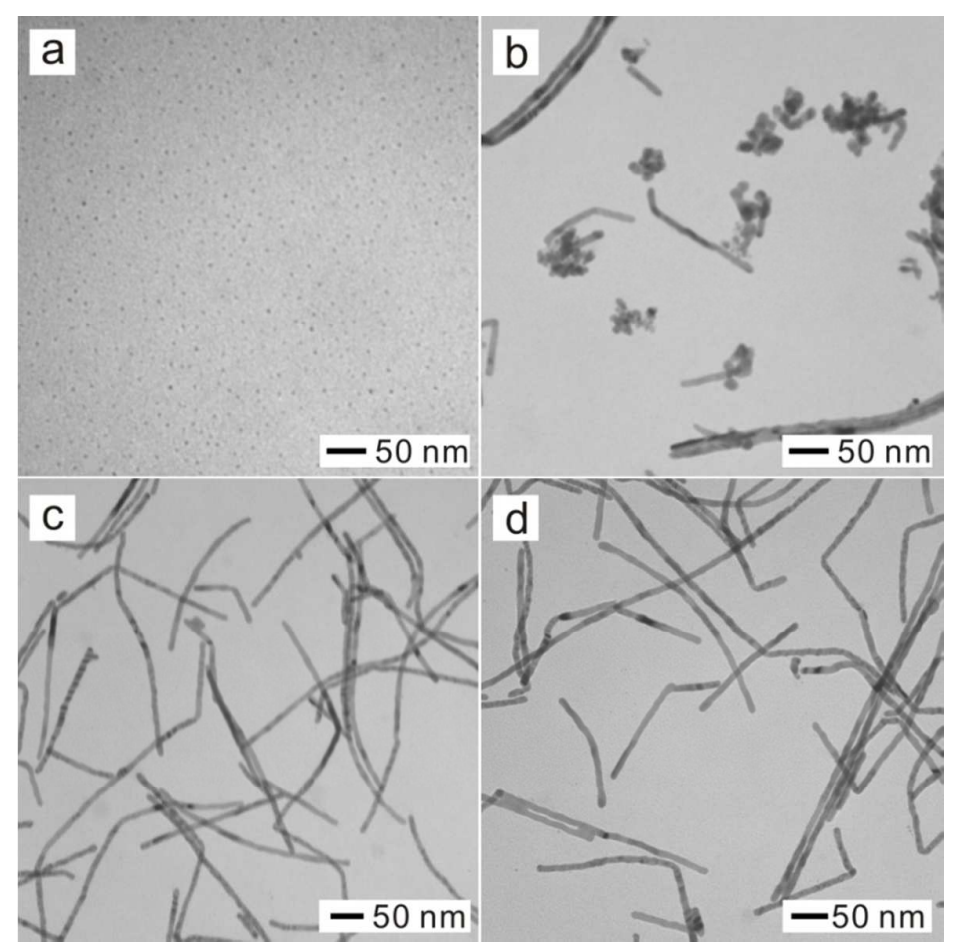

Figure S5. TEM images of Ag nanowires prepared at different temperatures. a) $80{ }^{\circ} \mathrm{C}$, b) $100^{\circ} \mathrm{C}$, c) $120^{\circ} \mathrm{C}$, and d) $150^{\circ} \mathrm{C}$. 

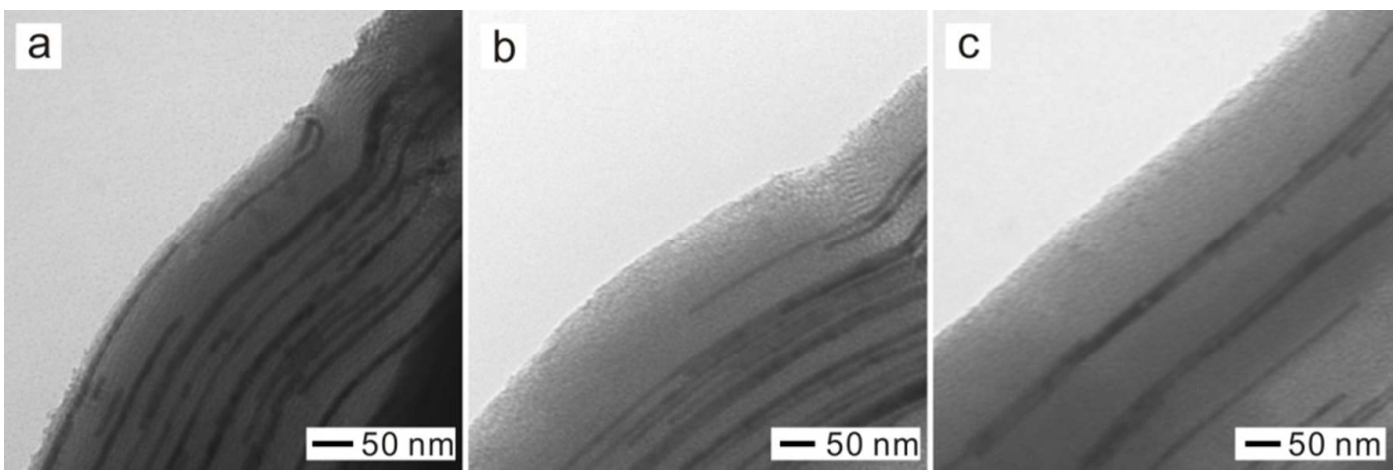

Figure S6. TEM images of Ag nanowires/SBA-15 obtained by annealed at different temperatures: (a) $180{ }^{\circ} \mathrm{C}$, (b) $300^{\circ} \mathrm{C}$, and (c) $500{ }^{\circ} \mathrm{C}$. 

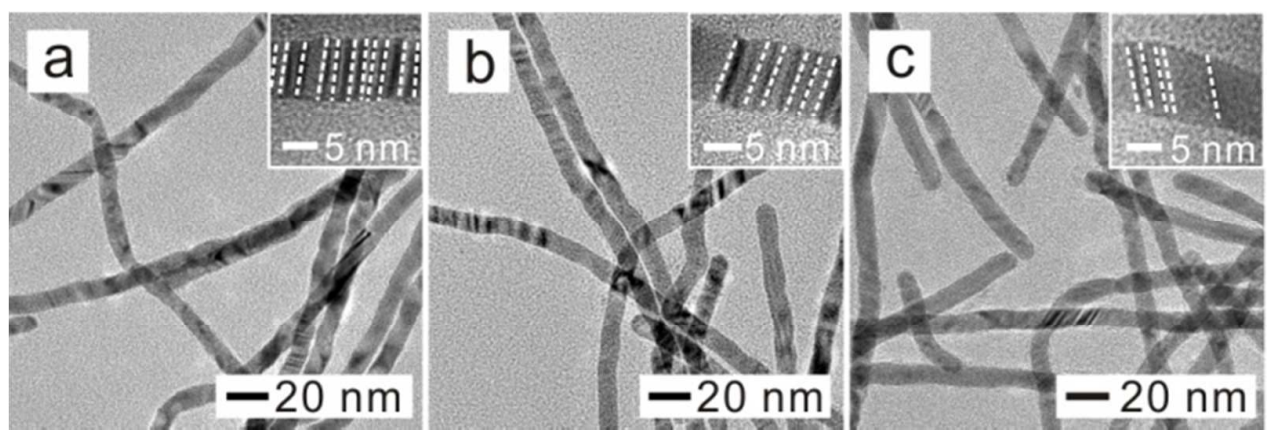

Figure S7. TEM and HRTEM images of Ag nanowires prepared under different annealing temperatures. a) $180{ }^{\circ} \mathrm{C}$, b) $300{ }^{\circ} \mathrm{C}$, and c) $500{ }^{\circ} \mathrm{C}$. Insets are the corresponding HRTEM images. The dashed white lines in HRTEM images show the defects in the nanowires. 
Table S1. Statistics results of defect densities of Ag nanowires prepared at different annealing temperatures.

\begin{tabular}{cccc}
\hline Samples & Ag NWs-180 & Ag NWs-300 & Ag NWs-500 \\
\hline Annealing temperature $\left({ }^{\circ} \mathrm{C}\right)$ & 180 & 300 & 500 \\
Defect density (per 10 nm) & 6.01 & 4.39 & 1.51 \\
Average defect length (nm) & 8.48 & 9.89 & 10.19 \\
\hline
\end{tabular}




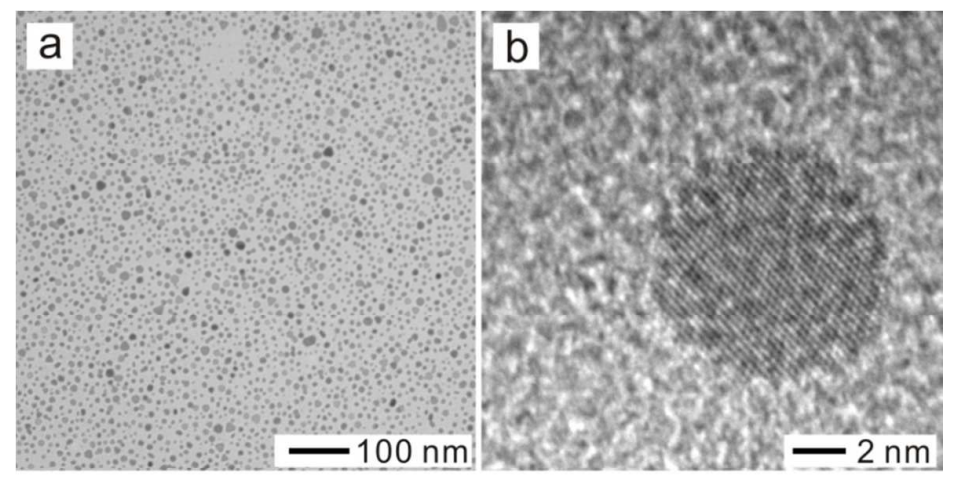

C

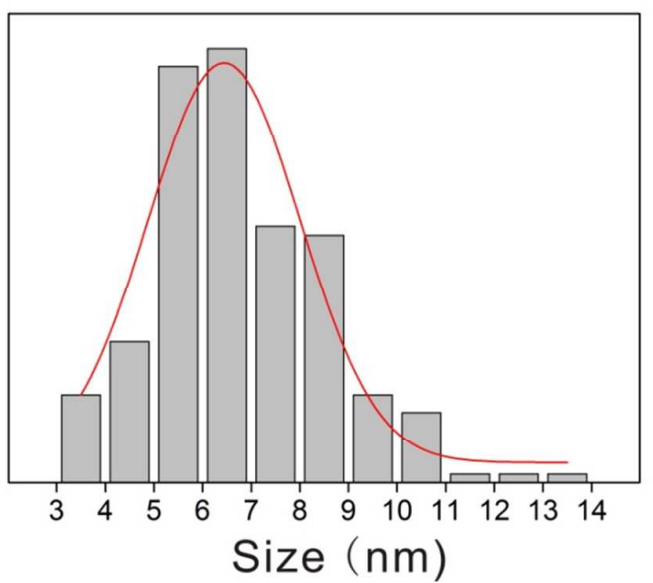

Figure S8. TEM and HRTEM images of the Ag nanoparticles. a) TEM image. b) HRTEM image. HRTEM image shows that the prepared Ag nanoparticles are of defect-free. c) Histogram of particle size distribution based on the measurement of above 200 nanoparticles. The average diameter of $\mathrm{Ag}$ nanoparticles is $6.77 \mathrm{~nm}$. 


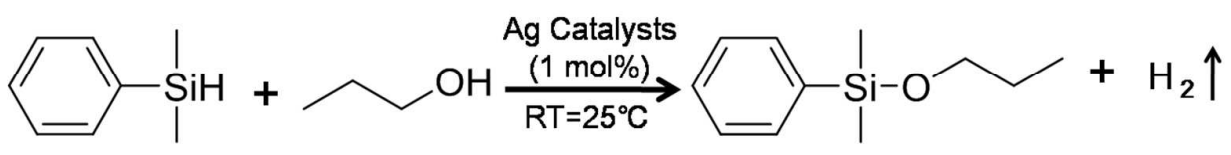

a)

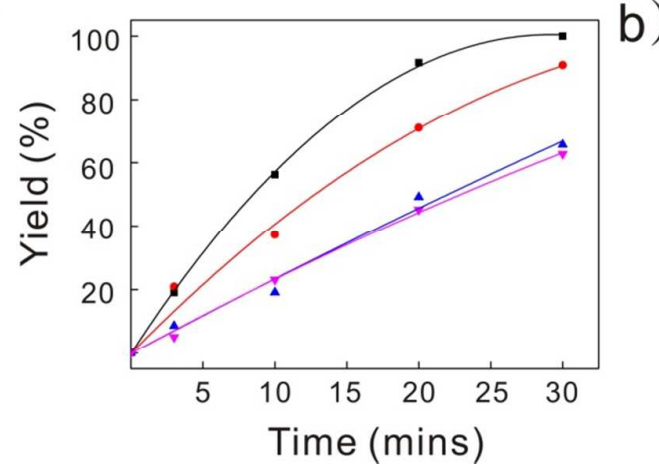

b)

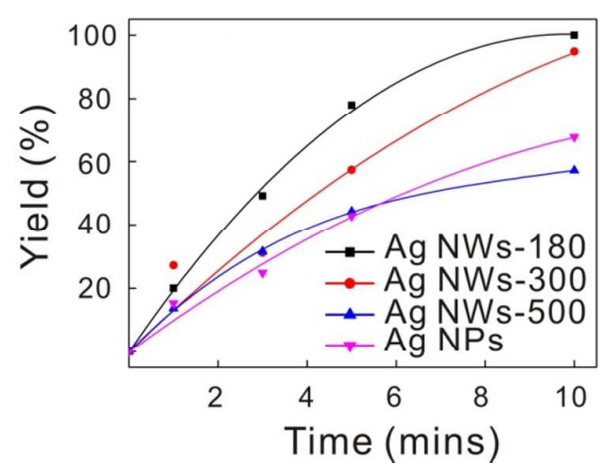

Figure S9. Time-conversion curves of dehydrogenative coupling reaction of dimethylphenylsilane with $n$-propanol at a) $45^{\circ} \mathrm{C}$ and b) $65^{\circ} \mathrm{C}$, respectively. 


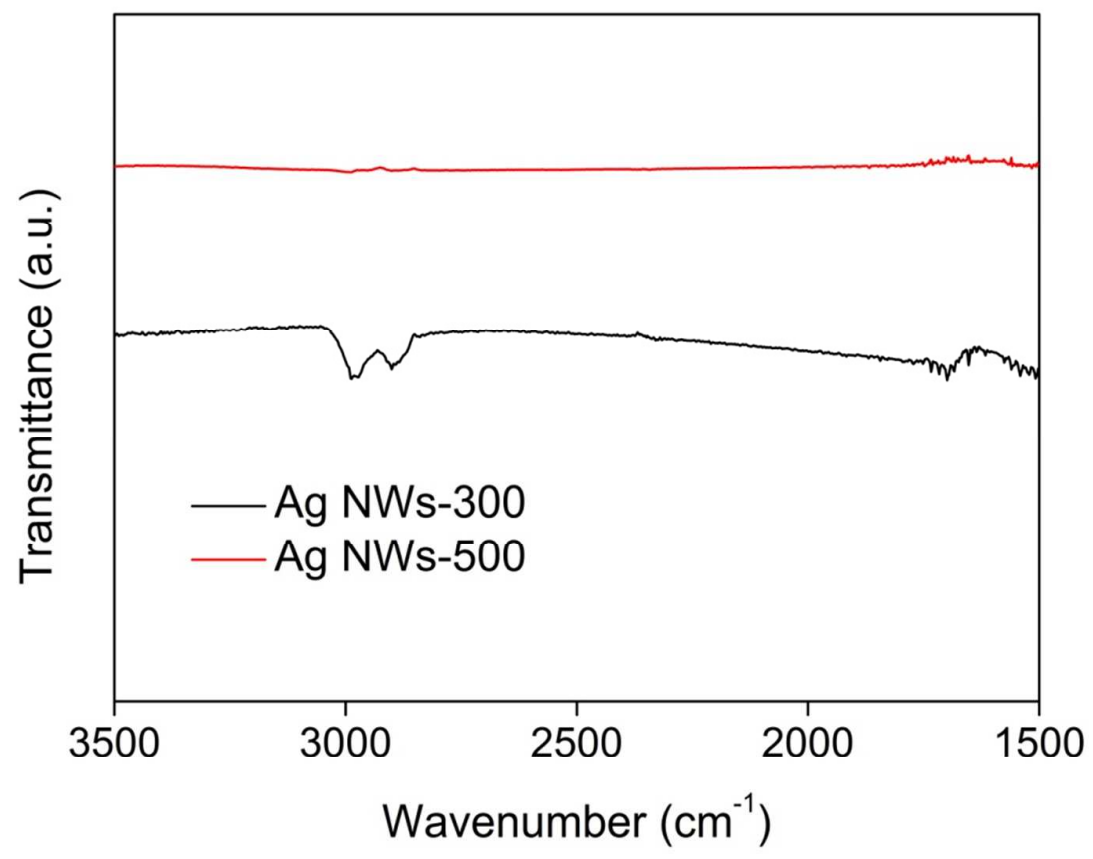

Figure S10. FT-IR spectra of dimethylphenylsilane on Ag NWs-300 and Ag NWs-500. 


\section{Turnover Frequency (TOF) experiments.}

$1 \mathrm{mmol}$ of dimethylphenylsilane was added into water which consists of $5 \times 10^{-4} \mathrm{mmol}$ Ag catalysts (Ag NWs or Ag NPs).

Ag NWs can be recognized as cylinders with a diameter of $8 \mathrm{~nm}$. The top and bottom surfaces of cylinders could be neglected due to the ultra-long size of Ag NWs. The percentage of the surface atoms of Ag NWs was calculated to be $9.7 \%$.

$\mathrm{TOF}_{\text {AgNWs-180 }}=(1 \mathrm{mmol} \times 0.067) /\left(1 / 6 \mathrm{~h} \times 5 \times 10^{-4} \mathrm{mmol} \times 9.7 \%\right)=8288 \mathrm{~h}^{-1}$

Ag NPs can be recognized as spheres with a diameter of $6.77 \mathrm{~nm}$. The percentage of the surface atoms of Ag NPs was calculated to be 15.8\%. According the same formula, the $\mathrm{TOF}_{\mathrm{Ag} \mathrm{NPs}}=1415 \mathrm{~h}^{-1}$. 
Table S2. Comparison of different heterogeneous catalytic systems reported for the oxidation of dimethylphenylsilane with water.

\begin{tabular}{|c|c|c|c|c|}
\hline Entry & Catalyst & $\begin{array}{c}\text { Temperature } \\
\left({ }^{\circ} \mathrm{C}\right)\end{array}$ & $\begin{array}{c}\text { Loading } \\
(\%)\end{array}$ & TOF $\left(h^{-1}\right)$ \\
\hline 1 & Ag NWs ${ }^{[\mathrm{a}]}$ (This work) & RT & 0.05 & 8288 \\
\hline 2 & Ag NPs (This work) & RT & 0.05 & 1415 \\
\hline 3 & Nanoporous $\mathrm{Ag}^{[1]}$ & RT & 0.3 & 576 \\
\hline 4 & $\operatorname{AgHAP}^{[2]}$ & 80 & 3 & $178^{[\mathrm{b}]}$ \\
\hline 5 & $\mathrm{Au} / \mathrm{SiO}_{2}{ }^{[3]}$ & RT & 0.4 & 59400 \\
\hline 6 & $\mathrm{AuCNT}^{[4]}$ & RT & 0.1 & 50480 \\
\hline 7 & $\mathrm{AuCNT}^{[5]}$ & RT & 0.001 & $12000^{[\mathrm{b}]}$ \\
\hline 8 & Nanoporous $\mathrm{Au}^{[6]}$ & RT & 1 & 10700 \\
\hline 9 & $\mathrm{AuCNT}^{[7]}$ & RT & 0.001 & 10167 \\
\hline 10 & $\mathrm{Au} \mathrm{NPs}^{[8]}$ & RT & 0.1 & $800^{[\mathrm{b}]}$ \\
\hline 11 & AuHAP ${ }^{[9]}$ & 80 & 0.83 & $40^{[\mathrm{b}]}$ \\
\hline 12 & $\mathrm{Pd} / \mathrm{C}-100 \mathrm{H}^{[10]}$ & 35 & 0.005 & 5714 \\
\hline 13 & Pt Nanocluster ${ }^{[11]}$ & RT & 0.1 & $190^{[\mathrm{b}]}$ \\
\hline 14 & $\operatorname{RuHAP}^{[12]}$ & 80 & 5 & $7^{[\mathrm{b}]}$ \\
\hline
\end{tabular}

[a] Ag NWs-180. [b] These results were calculated based on the metal loading. 
Table S3.Ag NWs-180 catalyzed oxidation of various substrates.

\begin{tabular}{cccccc}
\hline Entry & Silanes & $\begin{array}{c}\text { Oxidizing } \\
\text { Agent }\end{array}$ & $\begin{array}{c}\text { Temperature } \\
\left({ }^{\circ} \mathrm{C}\right)\end{array}$ & Time (mins) & Yield (\%) \\
\hline 1 & $\mathrm{Me}_{2} \mathrm{PhSiH}$ & $\mathrm{MeOH}$ & $\mathrm{RT}$ & 60 & 100 \\
2 & $\mathrm{Me}_{2} \mathrm{PhSiH}$ & $\mathrm{EtOH}$ & $\mathrm{RT}$ & 60 & 100 \\
3 & $\mathrm{Me}_{2} \mathrm{PhSiH}$ & $n \mathrm{BuOH}$ & $\mathrm{RT}$ & 60 & 100 \\
4 & $\mathrm{Me}_{2} \mathrm{PhSiH}$ & $\mathrm{H}_{2} \mathrm{O}$ & $\mathrm{RT}$ & 45 & 100 \\
5 & $\mathrm{Ph}_{3} \mathrm{SiH}$ & $\mathrm{H}_{2} \mathrm{O}$ & 50 & 90 & 100 \\
6 & $\mathrm{Et}_{3} \mathrm{SiH}^{\mathrm{b}]}$ & $\mathrm{H}_{2} \mathrm{O}$ & 50 & 150 & $>99$ \\
\hline
\end{tabular}

[a] Conditions unless otherwise stated: Silane $(1 \mathrm{mmol})$, oxidizing agent $(4.0 \mathrm{~mL})$, and Ag NWs-180 (1 mol\%). [b] Conditions unless otherwise stated: Silane (1 mmol), water $(0.75 \mathrm{~mL})$, tetrahydrofuran $(1.25 \mathrm{ml})$, and Ag NWs-180 (5 mol\%). 
a)

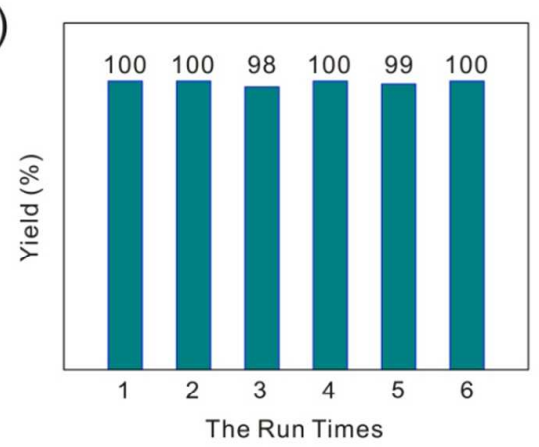

c)

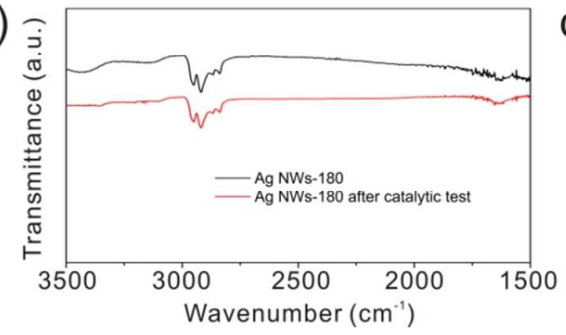

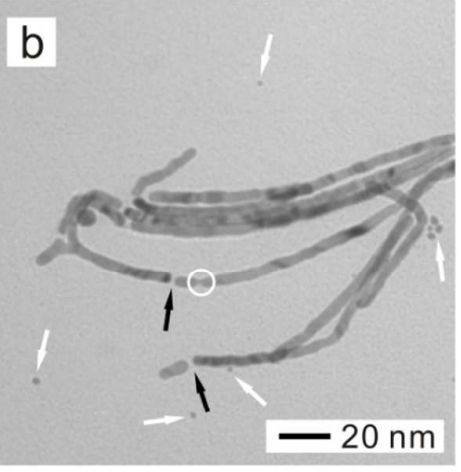

d)

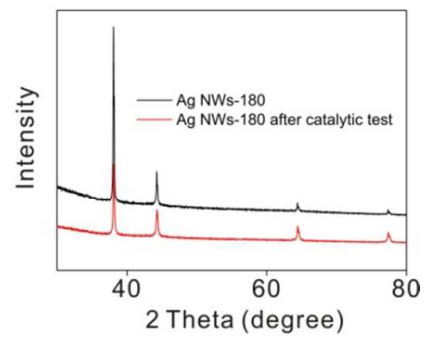

Figure S11. The stability test of Ag NWs-180 catalysts at $25{ }^{\circ} \mathrm{C}$. a) The yield histogram of stability test. b) TEM image of Ag NWs catalysts after six cycles. Only small range of Ag NWs has been damaged during the catalytic process, such as breaks (black arrows), dissolved nanoparticles (white arrows), and forthcoming break (white circle). c) FT-IR spectrum of dimethylphenylsilane on Ag NWs-180 after six cycles' catalytic reactions. d) XRD patterns of Ag NWs-180 and Ag NWs-180 before and after six cycles' catalytic reactions. 


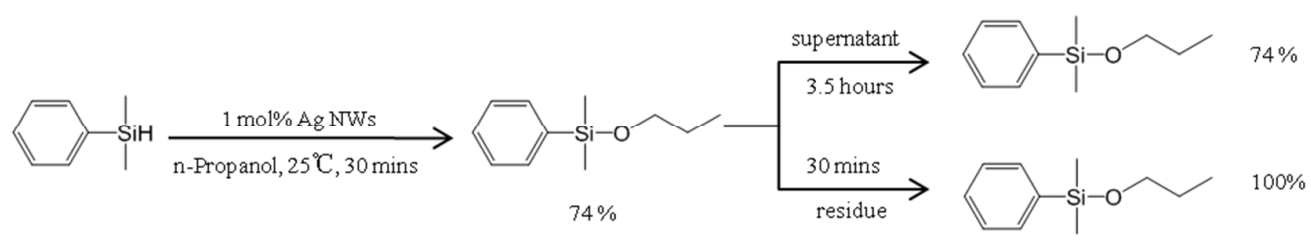

Scheme S1. Leaching test of Ag NWs-180 catalysts. When the conversion was $74 \%$, half of the reaction solution was taken out with Ag NWs being separated (supernatant), while the other half stayed unchanged (residue). Further stirring of supernatant under the same conditions with 3.5 hours did not yield any additional product.

Table S4. ICP-MS result of Ag NWs-180 catalysts after catalysis. After reaction, the catalysts were separated by centrifugation. Aqua forties was used to carbonization organic compounds and etching possible silver. The ppb level result shows there was no any silver drain during the reactions.

\begin{tabular}{cc}
\hline Sample & Concentration \\
\hline Ag NWs-180 & $4.81 \mathrm{ppb}$ \\
\hline
\end{tabular}


References:

[1] Z. Li, C. Zhang, J. Tian, Z. Zhang, X. Zhang, Y. Ding, Catalysis Communications 2014, 53, $53-56$.

[2] T. Mitsudome, S. Arita, H. Mori, T. Mizugaki, K. Jitsukawa, K. Kaneda, AngewandteChemie $2008,47,7938-7940$.

[3] W. Li, A. Wang, X. Yang, Y. Huang, T. Zhang, Chemical communications 2012, 48, 9183-9185.

[4] D. V. Jawale, E. Gravel, V. Geertsen, H. Li, N. Shah, R. Kumar, J. John, I. N. N. Namboothiri, E. Doris, Tetrahedron 2014, 70, 6140-6145.

[5] J. John, E. Gravel, A. Hagege, H. Li, T. Gacoin, E. Doris, AngewandteChemie 2011, 50, 7533-7536.

[6] N. Asao, Y. Ishikawa, N. Hatakeyama, Menggenbateer, Y. Yamamoto, M. Chen, W. Zhang, A. Inoue, AngewandteChemie 2010, 49, 10093-10095.

[7] T. Liu, F. Yang, Y. Li, L. Ren, L. Zhang, K. Xu, X. Wang, C. Xu, J. Gao, J. Mater. Chem. A 2014, 2, 245-250.

[8] V. Gitis, R. Beerthuis, N. R. Shiju, G. Rothenberg, Catalysis Science \& Technology 2014, 4, 2156-2160.

[9] T. Mitsudome, A. Noujima, T. Mizugaki, K. Jitsukawa, K. Kaneda, Chemical communications 2009, 5302-5304.

[10] K.-i. Shimizu, T. Kubo, A. Satsuma, Chemistry - A European Journal 2012, 18, 2226-2229.

[11] B. P. S. Chauhan, A. Sarkar, M. Chauhan, A. Roka, Applied Organometallic Chemistry 2009, 23, 385-390.

[12] K. Mori, M. Tano, T. Mizugaki, K. Ebitani, K. Kaneda, New Journal of Chemistry 2002, 26, $1536-1538$. 